\title{
Mediadores e literatura para crianças
}

\section{Resumo}

No campo da literatura para crianças, o lugar ocupado pelos adultos é considerado como o do mediador. $\mathrm{O}$ objetivo deste ensaio é reafirmar que esse lugar pertence aos signos e, para isso, recupera o conceito de signo ideológico em Volóchinov (1895-1936), a formação do psiquismo e a função mediadora dos signos em Vigotski (1896-1934) e o conceito precursor de mediadores em Sorokin (1889-1968). A tese a ser defendida considera os homens como seres humanos em relação mediada por signos organizados em gêneros, que compõem o campo da literatura para crianças. A conclusão aponta que as atitudes humanas, ao lidar com a literatura, podem vir a ser signos e que somente neste aspecto é que o homem pode fazer parte de um conjunto sígnico mediador.

Palavras-chave: Literatura infantil; Mediador; Signo ideológico; Fato social.

\section{Introdução ${ }^{1}$}

\author{
No campo da literatura para crian- \\ ças, o lugar ocupado pelos adultos - \\ bibliotecários, pais e professores - é
}

\footnotetext{
Possui graduação em Letras pela Universidade Estadual Paulista Júlio de Mesquita Filho (1972), graduação em Pedagogia pela Faculdade de Ciências e Letras de Votuporanga (1978), mestrado em Educação pela Universidade Estadual Paulista Júlio de Mesquita Filho (1991), doutorado em Educação pela Universidade Estadual Paulista Júlio de Mesquita Filho (1996) e Pós-Doutorado pela Universidade de Évora, Portugal (setembro a dezembro de 2007), financiamento FAPESP. Em novembro e dezembro de 2010, realizou estágio pós-doutoral junto ao Instituto Nacional de Pesquisas Pedagógicas (INRP), em Lyon, França. Pós-Doutorado pela Université-Sorbonne, Paris IV (08.10.2013 a 07.08.2014), com financiamento FAPESP. Livre-docente pela Universidade Estadual Paulista (UNESP) em 2013. Atualmente é professor Adjunto do Departamento de Didática e do Programa de Pós-Graduação em Educação da Universidade Estadual Paulista Júlio de Mesquita Filho, em Marília. Trabalhou como professor, diretor de escola e supervisor de ensino na rede pública estadual paulista. Tem experiência na área de Educação, com ênfase em Métodos e Técnicas de Ensino, atuando principalmente nos seguintes temas: leitura, alfabetização, leitura e escrita. Orientador no programa DINTER entre Universidade Federal do Maranhão e UNESP de Marilia (2008-2010) e no DINTER entre Instituto Técnico Federal do Ceará e UNESP de Marília (2012-2014). Pesquisador convidado do Laboratório Linguistique, Langues, Parole (LiLPa) da Faculté de Lettres, da Université de Strasbourg, França no período de 22 de setembro a 18 de dezembro de 2015. Orientador no Dinter entre UNESP de Marília e Instituto Federal de Rondônia de 2018 a 2022. E-mail: dagobertobuim@gmail.com
}

Data de submissão: dez. 2020 - Data de aceite: mar. 2021 http://dx.doi.org/10.5335/rdes.v17i01.11554 
consensualmente o lugar ocupado pelo mediador. Esse aspecto consensual vem, quero crer, da visão da aparência do fenômeno, porque há a percepção visual de um adulto que toma um livro nas mãos e intermedeia a relação da criança com esse livro e com seu conteúdo literário. Essa relação entre seres humanos, de gerações distintas, transposta para um esquema simplificado, acentua e justifica o consenso: há um livro com texto e ilustrações, parte da cultura humana, que compõe a literatura de um povo e que deve ser conhecido pelas novas gerações. $\mathrm{O}$ adulto estaria em posição intermediária, como neste esquema: livro de literatura - adulto - criança.

Analisado o esquema com as lentes da aparência não há como discordar do consenso. Como a função do investigador é a de pensar e de repensar constantemente suas abordagens de análise, alimentadas por diferentes princípios teóricos, é possível acoplar outras lentes e olhar para o mesmo processo por outra perspectiva. É esse exercício que pretendo fazer neste ensaio. Em palavras mais diretas, o objetivo é rever o papel de mediador atribuído ao adulto. Em vez de usar o termo mediação, optarei por usar o de mediador por se referir à uma manifestação concreta, ancorada em conjuntos de signos, mas a referência a outros estudos respeitará o termo empregado na fonte de origem. A tese a ser defendida pressupõe considerar os homens como seres humanos em relação mediada por signos organizados em gêneros que compõem o campo da literatura para crianças. Visto por esse prisma, o homem adulto não medeia, mas faz parte de um dos polos. Todavia, a tese considera também que o livro, isto é, a criação cultural humana, não se descola dos homens. Isso pressupõe que os homens criam histórias, livros, gestos e modos de ler e é esse conjunto que compõe o mediador. Portanto, as atitudes humanas, ao lidar com a literatura, são compostas por signos que se fundem a ela. Neste aspecto, e somente neste aspecto, é que o homem compõe o conjunto mediador, mas não ele mesmo, isoladamente, o ocupante desse lugar. Os argumentos arrolados para a defesa dessa tese compõem o desenvolvimento deste ensaio e incluem o pensamento de Valentin Volóchinov (1895-1936), de Lev Vigotski (1896-1934) e de Pitirim Sorokin (1889-1968).

As lentes teóricas que reinterpretam esse papel de mediador têm como referência os estudos de Vigotski sobre o conceito de mediador atribuído aos signos e, em um olhar mais amplo, a toda a cultura humana, porque os signos são os instrumentos de constituição do pensamento. Entre a geração adulta e a outra que nasce interpõem-se os signos, a cultura, a arte, e também a literatura para crianças, considerados os reais mediadores, porque portam com eles os gestos, os atos, os materiais, os instrumentos e os modos 
de operar humanos. De Volóchinov serão recuperados o conceito de signo ideológico no vasto mundo da criação ideológica, onde se situa a literatura para crianças e seu papel na formação da consciência. Os aportes vindos de Sorokin, via Tilkowski (2012), destacarão o conceito de fato social, o papel das trocas sociais entre os grupos humanos e, sobretudo, a origem do conceito de mediador e de sua estrutura. Tanto Vigotski quando Volóchinov podem ter se nutrido dos estudos de Sorokin para desenvolver algumas de suas teses sobre mediadores. É o que demonstrarei no último tópico.

Para perseguir a demonstração desta tese, o desenvolvimento do ensaio se apoiará também nos princípios de cultura como forma de humanização, da necessidade de se oferecer às crianças as formas ideais (VIGOTSKI, 2010) de cultura desde o nascimento, e no princípio de que o homem histórico, cultural e social se funde, pelos seus atos culturais, com sua criação, e pode, por isso, ocupar, somente nessa condição de signo, a função de mediador, porque essa função pertenceria exclusivamente aos signos.

\section{Os aportes da filosofia da linguagem e da teoria histórico-cultural}

Um dos pontos teóricos dos argumentos aqui apresentados tem como referência o caráter mediador do signo, considerado ideológico, especialmente o signo verbal escrito, matéria-prima da obra literária, e o signo de modo geral, instrumento pelo qual o homem compreende a realidade e age sobre ela. Por essa razão, é necessário compreender a noção de signo ideológico, o lugar que ele ocupa na criação da cultura humana e a sua ligação com os meios de produção da base econômica; dito de outro modo, o lugar que ele ocupa na superestrutura social, no mundo ideológico, e seus vínculos com a infraestrutura. Essa abordagem foi bem discutida por Volóchinov em sua obra mais conhecida no Brasil - Marxismo e Filosofia da Linguagem: "O problema da correlação entre a base e as superestruturas [...] pode ser, em grande parte, compreendido justamente no material da palavra" (VOLÓCHINOV, 2017, p. 106). A base seria constituída pelas relações humanas direcionadas para e pela produção econômica. As relações refletiriam a organização econômica, a relação entre capital e trabalho, a produção de bens, o acesso a eles, a sua distribuição e a sua partilha.

São essas relações de base, de infraestrutura, que estabelecem vínculos estreitos com a criação cultural humana, situada em outro patamar das relações, na superestrutura, já que "a essência desse problema se reduz a como a existência real (a base) determina o signo, e como o signo reflete e refrata a existência em formação" (VOLÓCHINOV, 2017, p. 106. 
grifos do autor). Não há, portanto, reflexo da realidade de uma instância à outra, mas refração, porque a criação cultural, cuja matéria é o signo, interpreta essa realidade conforme são estabelecidas as relações dos homens que a recriam.

No reino da criação literária para crianças, o livro com suas histórias seria o objeto mediador entre o homem e a realidade; a palavra verbal escrita e as imagens refratadas assumiriam profundamente a sua função de signos ideológicos que se situam na relação entre $o$ adulto e a criança que chega ao mundo, uma vez que

[...] a palavra participa literalmente de toda interação e de todo contato entre as pessoas [...] Na palavra se realizam os inúmeros fios ideológicos que penetram todas as áreas da comunicação social. (VOLÓCHINOV, 2017, p. 106).

A literatura infantil, como criação cultural, então, penetra e compõe a comunicação social.

A tradução do russo para o francês feita por Sériot e Tilkowski-Ageeva da obra acima citada de Volochinov substitui a expressão "comunicação social" por "troca social” (VOLOŠINOV, 2010, p. 151), mais próxima das relações humanas, pelas quais os homens dão e recebem os bens culturais já criados. Desse ponto de vista, a literatura para crianças, como bem cultural, permite que adultos e crianças troquem gestos, intenções, saberes, condutas, sentidos e aprecia- ções. O signo, aparentemente fixado nos suportes, é sensível às mudanças sociais que se desenrolam na infraestrutura: "É bastante óbvio que a palavra será o indicador mais sensível das mudanças sociais, sendo que isso ocorre lá onde essas mudanças estão se formando, onde elas ainda não se constituíram em sistemas ideológicos organizados" (VOLÓCHINOV, 2017, p. 106, itálicos no original), isto é, na infraestrutura. O signo verbal, na essência de seus sentidos, se modifica conforme são modificadas as trocas e as mudanças sociais, porque ele mesmo dá condições para a criação das relações e para a recriação ininterrupta da cultura. Concebe-se, consideradas essas condições, o seu papel de mediador sensível.

A palavra artística escrita, inscrita em suportes diversos, é manifestação concreta do ser humano que dela faz seu instrumento de recriação da realidade, de criação da cultura e de troca social entre homens e entre gerações. Há, entretanto, outras manifestações e criações sígnicas além do campo da palavra verbal que compõem um conjunto ao qual Volóchinov (2017, p. 93, grifo autor) nomeia como o universo ou o mundo dos signos: "desse modo, além dos fenômenos da natureza, dos objetos tecnológicos e dos produtos de consumo, existe um mundo particular: o mundo dos signos". Ora, esse mundo povoado de signos não seria constituído por signos-palavras apenas, mas por muitos outros, porque 
"os signos também são objetos únicos e materiais e, como acabamos de ver, qualquer objeto da natureza, da tecnologia ou de consumo pode se tornar um signo." (VOLÓCHINOV, 2017, p. 93).

Pode-se entender que os gestos são signos, a conduta e a expressão física e intelectual humanas são signos. Portanto, o adulto bibliotecário/professor/pai pode compor, ao se relacionar com a criança por meio do livro, e com ele também, um conjunto sígnico, isto é, um conjunto semiótico. Esta hipótese será retomada mais ao final deste ensaio. Por ora, é preciso destacar a natureza ideológica dos signos, entre os quais as palavras e as ilustrações de uma obra, e, por que não, as expressões, os olhares, os gestos, as apreciações, os julgamentos visíveis, audíveis e as intenções percebidas.

A função e a natureza do signo são determinantes para a compreensão da realidade, na qual se inclui o homem, porque são, ao mesmo tempo, instrumentos de compreensão da realidade e instrumentos de formação da consciência humana, portanto, profundamente essenciais ao longo da vida e por meio dos quais são feitas as escolhas e são tomadas as decisões que formarão o psiquismo:

Qualquer produto ideológico é não apenas uma parte da realidade natural e social seja ele um corpo físico, um instrumento de produção ou um produto de consumo - mas também, ao contrário desses fenômenos, reflete e refrata outra realidade que se encontra fora dos seus limites. Tudo o que é ideológico possui uma significação: ele representa e substitui algo encontrado fora dele, ou seja, ele é um signo. Onde não há signo também não há ideologia. (VOLÓCHINOV, 2017, p. 91).

Quais são os destaques dessa citação para o que aqui interessa? A ideia de que o produto ideológico que se situa na superestrutura, portanto no reino da criação cultural humana, refrata a realidade a seu modo, mas não a reproduz, nem dela faz uma cópia, é um dos destaques. A refração da realidade e a função do signo são referendadas por Volóchinov (2017, p. 93):

[...] o signo não é somente uma parte da realidade, sendo por isso mesmo capaz de distorcê-la, ser-lhe fiel, percebê-la de um ponto de vista específico, e assim por diante.

O segundo destaque é o de que um corpo físico, não como parte da realidade, mas tomado como algo que remete a uma significação fora dele, pode vir a ser um signo. Adiante este aspecto será retomado quando Sorokin será chamado a contribuir para a argumentação. Pode-se pensar no corpo humano não como um corpo biológico, mas como instrumento de uma consciência que faz trocas com outras, como no caso da sessão de leitura, da partilha de atos de ler livros de literatura com crianças. Nesse caso, pode-se reiterar: a consciência e o corpo físico fundidos se tornam signo. O terceiro destaque se refere ao valor ideológico do signo, isto é, há sempre apreciação 
valorativa na percepção e na manifestação humana por signos, os mediadores fundamentais das trocas sociais.

Em suma: os signos, sejam quais forem, têm natureza ideológica e, portanto, portam valores sujeitos a apreciações e julgamentos. As relações de troca cultural entre gerações, em que a literatura para crianças ocupa o papel de mediadora, são constituídas por signos visuais, enunciados verbais escritos, ilustrações, gestos, expressões corporais, enunciados verbais orais, entonações, ênfases, timbres, todos eles prenhes de valores e de ideologia, fundamentais para a formação da consciência e da própria condição humana.

\section{As formas ideais de cultura em Vigotski}

Vigotski atribui fundamental papel às formas ideais de cultura no processo de humanização das crianças como seres da espécie em desenvolvimento ontogenético e filogenético. O entorno cultural, isto é, o meio - e aqui estão incluídos a criação cultural e os homens que as criam, as distribuem e as manipulam - desempenha função incontornável na formação do psiquismo e no legado cultural entre gerações. Entre essas formas ideais de cultura destaco a invenção histórica e cultural da literatura para crianças, sua divulgação e sua prática social. Para melhor compreender esse conceito de forma ideal é preciso recorrer a suas observações sobre a relação entre o meio, entendido como o entorno cultural, e o desenvolvimento da criança. $\mathrm{O}$ autor faz uma indagação inicial sobre isso, ensaia uma resposta com o intuito de delinear gradativamente o conceito:

Em que consistem essas relações específicas entre o meio e o desenvolvimento, se falamos sobre o desenvolvimento da personalidade da criança, sobre as qualidades específicas do homem? A mim me parece que essa particularidade consiste no seguinte: no desenvolvimento da criança, naquilo que deve resultar ao final do desenvolvimento, como resultado do desenvolvimento, e que já está dado pelo meio logo de início. E não somente dado pelo meio logo de início, mas, também, influente nas etapas mais primevas do desenvolvimento da criança (VIGOTSKI, 2010, p. 693).

A incorporação do pensamento de Vigotski e desses trechos de sua autoria deriva da minha intenção de analisá-los com as lentes dos estudos da literatura considerada criação constituinte da cultura humana, composta não somente pelo objeto cultural, mas pelos atos culturais humanos que a impregnam desde a sua criação, pela escolha dos suportes, pelos modos de circulação, pelos modos de ler e pelos modos de a apreciar. Orientado por esse olhar, as palavras de Vigotski insistem que a formação intelectual esperada no final do desenvolvimento do homem deve estar já no seu entorno desde o início de sua vida. Se os homens e suas instituições esperam e desejam que os adultos 
das gerações emergentes sejam leitores de literatura, ou mesmo recriadores de literatura, é necessário que essa forma ideal de cultura, integral e complexa, não somente como objeto isolado, mas como objeto nas relações humanas, faça parte do universo infantil desde os primeiros momentos de seu desenvolvimento. Se houver a ausência dessa forma ideal na infância, se as crianças forem dela privadas, ficarão à margem de um aspecto da cultura humana, essencial para seu desenvolvimento ontogenético, com consequências para o desenvolvimento filogenético.

O conceito de forma ideal se esboça um pouco mais em Vigotski (2010), ao entender que essa forma é a ideal, a esperada, a desejada, ou, ainda, a necessária, a crucial para o desenvolvimento pleno do homem. É como se fosse um ponto de chegada (embora o ponto de chegada sempre se desloque) do desenvolvimento desejado:

Combinemos que essa forma desenvolvida, que deverá aparecer no final do desenvolvimento infantil, será chamada, assim como fazem na pedologia contemporânea, de forma final ou ideal - ideal no sentido de que ela consiste em um modelo daquilo que deve ser obtido ao final do desenvolvimento - ou final - no sentido de que é esta a forma que a criança, ao final de seu desenvolvimento, alcançará. (VIGOTSKI, 2010, p. 693).

Ocultar a forma ideal na infância é colocar obstáculos ao desenvolvimento intelectual, cultural, social do homem. Significa, portanto, retardar o processo de humanização. Com um olhar imbuído pela importância da literatura para as crianças, compreende-se que os adultos, os livros lidos e por eles manipulados em suas relações compõem uma forma ideal que desde os primeiros momentos da vida promovem o desenvolvimento intelectual, social e psíquico:

A maior particularidade do desenvolvimento infantil consiste em se tratar de um desenvolvimento que ocorre em condições de interação com o meio, quando a forma ideal, a forma final, esta que deverá aparecer ao final do desenvolvimento, não somente existe no meio e concerne à criança logo desde o início, mas realmente interage, realmente exerce influência sobre a forma primária, sobre os primeiros passos do desenvolvimento infantil, ou seja, em outras palavras, há algo, algo que deve se construir bem ao final do desenvolvimento, e que, de alguma maneira, influencia logo o início desse desenvolvimento. (VIGOTSKI, 2010, p. 693).

As assertivas a respeito do papel da literatura podem até ser contestadas, porque adultos ávidos leitores de literatura podem não ter tido a oportunidade de viver em um meio cultural quando crianças. Ou, em caminho inverso, crianças que viveram situações culturais com essas formas ideais não mantiveram quando adultas as mesmas atitudes intelectuais. Somente pesquisas específicas poderiam encontrar razões, acontecimentos, situações de vida, relações humanas que explicariam essas hipóteses. Vigotski (2010), de seu lado, mencionava, ainda que de modo bem genérico, pesquisas que indicavam ser 
a ausência da forma ideal desde o início um obstáculo ao desenvolvimento pleno. Ao trazer a observação para a temática deste ensaio, levanto a hipótese de que os leitores adultos de literatura que não leram a literatura na infância não terão o mesmo desenvolvimento no ponto de chegada em relação àqueles que a leram. Assim se manifesta Vigotski (2010, p. 695) sobre isso:

[...] pesquisas mostram que iriam, mas de forma extraordinariamente singular, isto é, as ações sempre irão se desenvolver de modo muito lento, muito particular e nunca atingirão aquele nível que atingiriam quando existe no meio uma forma ideal correspondente.

Por fim, Vigotski (2010) insiste que o processo de formação humana toma como princípio o processo de apropriação da cultura, em todas as suas formas e manifestações, portanto, de todas as suas formas ideais constituídas pela cultura material e pela cultura imaterial impregnadas pelas intenções, gestos e atitudes humanas.

Essas formas ideais influenciam a criança desde os primeiros passos que ela dá rumo à dominação da forma primária. E, no decorrer de seu desenvolvimento, a criança se apropria, transforma em suas aquisições interiores aquilo que, a princípio, era sua forma de interação externa com o meio. (VIGOTSKI, 2010, p. 698).

Ao entender a literatura para crianças e os modos como os homens a criam, a usam e a transmitem como um conjunto semiótico, quero compreender que as gerações humanas em uma cultura determinada, em um espaço geográfico determinado, tomam esse conjunto como o mediador de suas relações. Esse conjunto mediador porta, em seu núcleo, a materialidade, a imaterialidade e os atos culturais humanos. Os signos medeiam as relações, por isso os atos humanos também compõem esse universo sígnico. Entretanto, há um duplo papel para o homem: é mediado - o primeiro papel porque está nas relações em que a forma ideal ocupa o lugar de mediador, mas ao usar e ao se impregnar da forma ideal - o segundo papel - ele se funde com o livro pela forma ideal de lê-lo, de usá-lo, por isso se torna também um signo que contribui para a composição do conjunto semiótico da forma ideal de mediador. A criança não se apropria da literatura como uma forma ideal isolada do homem, mas se apropria dela por inteiro, impregnada pelos atos humanos específicos de ler literatura.

\section{A função mediadora dos signos em Vigotski}

Para abordar a temática dos signos como mediadores e a que enfatiza a necessidade de desenvolvimento cultural do homem, convém esclarecer que o fio condutor para essa abordagem será feito pelos fios tecidos por Nascimento (2014) ao estudar esses conceitos em Vigotski (2010). 
A respeito da cultura e de seu papel na formação humana, Nascimento (2014) registra que Vigotski vê

[...] o desenvolvimento cultural como "o domínio de meios externos da conduta cultural e do pensamento, ou o desenvolvimento da linguagem, do cálculo, da escrita, da pintura, etc." (VYGOTSKI, 1930/1995b, p. 34 apud NASCIMENTO, 2014, p. 144).

É nesse universo cultural que se insere a literatura para crianças e seu papel no desenvolvimento pleno do homem, resultante das relações entre os homens no mundo social, porque

Para Vygotski (1930/1995d, p. 150), a etapa externa da história do desenvolvimento cultural é social, ou seja, encontra-se no conjunto das relações humanas. Vygotski (1930/1995d, p. 150) entende que, por trás do desenvolvimento de todas as funções superiores, estão as relações sociais - as relações humanas. [...] "cada forma nova de experiência cultural não surge simplesmente desde fora, independentemente do estado do organismo no dado momento de desenvolvimento, mas que o organismo, ao assimilar as influências externas, ao assimilar toda uma série de formas de conduta, as assimila de acordo com o nível de desenvolvimento psíquico em que se encontra." (VYGOTSKI, 1930/1995d, p. 155 apud NASCIMENTO, 2014, p. 145).

É importante destacar na citação a ideia de que o desenvolvimento do homem depende de suas relações com os outros homens, logo, a criança tanto mais se desenvolve culturalmente quanto mais se relacionar com os adultos que estão no outro polo do esquema de relações em que uma manifestação cultural criada e em permanente recriação, como a literatura, ocupa o lugar de mediador. O que medeia a relação entre eles é esse bem cultural composto por um conjunto semiótico complexo. Esse conjunto é gradualmente apropriado pela criança, isto é, "toda uma série de formas de conduta". Isso vai ser fundamental na sua formação e em seu processo de humanização.

Esse conjunto de signos exerce o papel de mediador entre as duas gerações, uma vez que

[...] para Vygotski (1930/1995d), é graças ao signo que se estabelece a comunicação, pois, o signo é o traço fundamental do desenvolvimento superior das relações mediadas dos homens (NASCIMENTO, 2014, p. 188).

Ao se referir às relações humanas como mediadas, Vigotski sugere que existe entre os homens algo que os medeia, isto é, os signos, e com uma visão mais ampliada pode-se afirmar que são os bens culturais compostos por signos, e, sob uma visão mais específica, a literatura para crianças em qualquer forma física ou virtual impregnada dos gestos humanos. Nas relações entre adultos e crianças há uma abundância sígnica que estreita $o$ vínculo entre um e outro, que vem a fortalecer o elo de desenvolvimento cultural e intelectual da espécie.

Apesar de o protagonismo do mediador ser assumido pelos signos, 0 adulto se funde a eles, porque as suas práticas e os seus gestos são também signos. Portanto é ele, como afirmei antes, nessa condição 
de signo também um mediador, como Nascimento (2014) destaca:

Desde os primeiros dias do desenvolvimento, toda a história do desenvolvimento psíquico da criança nos mostra que consegue adaptar-se ao entorno, graças à mediações sociais, por intermédio das pessoas que a rodeiam. O caminho da coisa à criança $\mathrm{e}$ desta à coisa, passa por intermédio de outra pessoa. A transição desde a via biológica à social do desenvolvimento é a conexão chave no processo de desenvolvimento, um ponto de inflexão crucial na história do comportamento da criança. Nossos experimentos demonstram que o caminho por intermédio de outra pessoa é a autoestrada [rodovia, via de circulação] central do desenvolvimento da inteligência prática. Aqui, a fala desempenha um papel primordial. (VYGOTSKI; LURIA, 1931/2007, p. 28-29 apud NASCIMENTO, 2014, p. 197).

As palavras de Vigotski sobre o desenvolvimento da criança dão protagonismo às mediações sociais, isto é, aos homens que estão no entorno da criança e que se situam no caminho entre a criação cultural, a coisa, e ela, a criança. A criação pode ser o livro de literatura. Entretanto, essa coisa não é um objeto isolado dos atos humanos, dos usos humanos, do fazer humano. A coisa, o objeto, a história criada, porta com ela esses atos todos que são, em síntese, o conjunto semiótico já aqui referido. É necessário considerar, por essa razão, que o homem não é o mediador entre a criança e o bem cultural, mas ele próprio encarna o bem e a ele dá vida. $\mathrm{O}$ homem adulto não seria simplesmente uma estrada, como sugere a metáfora de Vigotski. Se assim fosse, os signos e todo o conjunto semiótico não seriam os mediadores, mas os mediados, e a função de mediador, a de estrada, seria a do adulto, mas isso contraria os princípios que atribuem aos signos essa função.

É clássico o argumento entre vigostkianos de que se a humanidade sofresse uma hecatombe e se somente um ser humano recém-nascido sobrevivesse, ele não se apropriaria da cultura humana, mesmo se os bens culturais continuassem existindo, porque não haveria o outro homem adulto que o ensinasse a compreender e a usar os bens culturais. Como vem sendo discutido até aqui, a coisa não se separa do homem e o homem não se separa da coisa.

\section{Fatos sociais e mediadores}

Por quem o conceito de mediador teria entrado no cenário russo nos anos 1920? Para comentar essa interrogação que a mim me fiz, foi necessário recorrer aos estudos de Tilkowski (2012) sobre o contexto intelectual em que Volóchinov se nutria. Entre os sociólogos da época, a pesquisadora encontrou nos estudos sociológicos de Pitirim Sorokin as pistas que estabeleciam o elo entre esses dois pesquisadores. Volochinov não teria tido contato direto com Sorokin, mas o conhecimento de sua obra teria sido feito por meio dos estudos de Pavel Sakulin (1868-1930) de quem ele era próximo 
e com quem convivera em Nevel, nos duros tempos da crise econômica russa. Sorokin publicara dois tomos de $O$ sistema de sociologia, muito citado por Sakulin, com previsão de oito volumes. $\mathrm{O}$ primeiro cuidou da interação entre os indivíduos e o segundo da interação entre grupos sociais. Os demais não foram publicados, porque ele foi expulso da Rússia pelos bolcheviques em 1922 e se instalou posteriormente nos Estados Unidos (TILKOWSKI, 2012).

Sorokin considera a interação entre dois indivíduos como o fato elementar de toda a vida social constituída pela interação entre grupos de indivíduos e grupos sociais. Para ele, "as vivências psíquicas [psixiceskie perezivanija] ou os atos exteriores [vnesnie akty] de um indivíduo mudam em função das vivências e dos atos exteriores de um outro (ou de outros) indivíduo(s)". (SOROKIN [1920] 1993:102, apud TILKOWSKI, 2012, p. 2017). Para analisar esse fato social elementar, é proposto um método objetivo que considere "os atos, os movimentos, os gestos, as mímicas, o conteúdo da fala, a entonação, etc., como fato exterior observável" (TILKOWSKI, 2012, p. 217). Os estudiosos das obras de Volóchinov e de Vigotski encontram neste trecho pontos de contato entre os três, especialmente em relação à noção de troca, formação social do psiquismo e os signos exteriores como objetos de estudo. O conceito de mediador vai se constituindo a partir desse outro, do fato social elementar e de sua estrutura, assim concebida por Sorokin, conforme registra Tilkowski (2012, p. 218):

Sorokin define o fato elementar como um fenômeno com três componentes: (1) ao menos dois indivíduos que condicionam mutualmente sua vivência e seu comportamento; (2) os atos pelos quais os indivíduos se influenciam uns aos outros; e (3) os "mediadores" [provodnik konduktori] que veiculam os atos de um indivíduo a outro (ibi:142).

Os mediadores entre os homens são os signos exteriores, instrumentos que permitem a troca de atos sociais e, consequentemente, dão as condições para que os homens se influenciem mutuamente na formação de suas consciências. Antes, portanto, de Vigostki e de Volóchinov, Sorokin já tinha esclarecido o conceito de mediador e apontado quem são esses mediadores. Mais interessante ainda é o aprofundamento da conceituação que revela ser ele uma das possíveis fontes de onde Volóchinov e seus amigos, entre os quais Medvedev (1892-1938), Bakhtin (1895-1975) e Jakubinskij (1892-1945) teriam bebido a água que os levaria a escolher o diálogo amplo, não somente o face a face, como matriz das relações humanas. Para Tilkowski (2012, p. 219),

Sorokin define os "mediadores" como os fenômenos que permitem interagir não somente as pessoas que se encontram em presença física imediata, mas também aquelas que estão separadas do ponto de vista espacial e temporal. 
Os estudos de Tilkowski revelam que Sorokin, em 1913, bem antes de Volóchinov, de seus amigos e de Vigotski, discutia o conceito de símbolo e de seu papel na vida social, em um tipo precursor de estudos semióticos. Os símbolos seriam os mediadores, isto é, os signos, uma vez que "Sorokin designa por mediadores os símbolos ou os signos que ele define como 'as formas externas de todo pensamento [mysl'] e de todo ato consciente". (SOROKIN, 1913:10 apud TILKOWSKI, 2012, p. 219). As fontes de Sorokin para analisar o conceito de símbolo estariam, para Tilkowski, nos estudos linguísticos de Humboldt (1767-1835) - a quem Volóchinov situa no campo do subjetivismo idealista - e retomados por Potbenjá (1835-1891). Tilkowski (2012, p. 220, grifos do autor) o encontra em Sorokin para quem

[...] a palavra humana é inteiramente simbólica já que ela exprime o pensamento, que 'a vida social não é outra coisa senão o simbólico' ou um processo de troca de símbolos. Se Sorokin faz a distinção entre os 'símbolos' e os 'símbolos de símbolos' (ou símbolos de segundo, terceiro graus, etc.), no Sistema sociológico, ele opõe 'mediadores físicos' e 'mediadores simbólicos'

Neste trecho, parte de uma nota de rodapé, que considero muito importante para restar assim tão afastada do núcleo dos comentários referenciados, estão inclusos a noção tão cara a Volóchinov de troca social por meio de signos/símbolos, quanto o pensamento de Vigotski ao se referir à escrita como um símbolo de segunda ordem, ao tomar a linguagem oral como de primeira ordem: "é natural que uma fala sem sonoridade real, somente imaginada e representada, que exige simbolização de segunda ordem, resulte à criança tão difícil em relação à fala oral como a álgebra em relação à aritmética" (VIGOTSKI, 2012, p. 340). Sorokin e Vigotski se encontram na expressão "segunda ordem", tão citada entre os vigotskianos.

Um dos objetivos anunciados na introdução deste ensaio fazia referência ao debate do papel de mediador conferido a professores, bibliotecários, como profissionais, ou a qualquer ser humano, em qualquer etapa da vida, quando introduz o outro na cultura humana, nas criações ideológicas, entre as quais se acomoda a literatura para crianças. As incongruências, divergências ou deslizes conceituais certamente se manifestam em virtude de opções teóricas distintas, de pontos de ancoragens não próximos uns dos outros. Para os que querem se situar no campo dos estudos do enfoque Histórico-Cultural, como Vigotski, ou em um dos campos da Filosofia da Linguagem no qual se abriga Volóchinov, convém melhor esclarecer o lugar de onde aqueles se posicionam para observar, na conceituação de Sorokin, o fato social elementar, a troca social por meio de signos e a distinção entre mediadores físicos e mediadores simbólicos, para quem “o 'mediador' é 
uma rede intermediária entre dois fatos psíquicos" (TILKOWSKI, 2012, p. 220).

Para discutir o papel simbólico de um mediador físico, Sorokin faz referência ao uso de um pano vermelho em países e situações não coincidentes. Em um país em tempos de paz, um trapo vermelho içado na rua causa especulações entre os transeuntes a respeito de seus sentidos e objetivos de quem o içou. Em um país estremecido por movimentos revolucionários, os sentidos serão outros. Nas duas situações, "o indivíduo que o içou pode condicionar o comportamento de outras pessoas pelas propriedades puramente físicas desse mediador" (TILKOWSKI, 2012, p. 221, grifos do autor), mas

[...] o indivíduo que iça uma bandeira vermelha determina e influencia o comportamento dos outros, menos pelas propriedades físicas do mediador, do que pela significação simbólica pela qual o mediador deve comunicar, 'assinalar' às outras pessoas. (SOROKIN apud TILKOWSKI, 2012, p. 221).

Essas afirmações de Sorokin, encontram-se, para Tilkowski (2012, p. 221), em Marxismo e Filosofia da Linguagem, de Vološinov, notadamente ao encontrar nessa obra a afirmação de que "o signo tem uma significação que ultrapassa seu caráter de dado singular”, sem, entretanto, fazer qualquer referência a Sorokin. O professor/bibliotecário/ ou qualquer ser humano, em seu aspecto físico, por si só não é um mediador, mas poderá vir a ser, se compuser um amplo conjunto semiótico a ser apropriado pela geração emergente. Ainda em Volóchinov há referência mais próxima à simbologia do tecido vermelho de Sorokin, ao fazer referência à foice e ao martelo no emblema da URSS como símbolos ideológicos em vez de apenas uma imagem do objeto. Reafirma o que dissera Sorokin: "todo corpo físico pode ser também percebido como uma imagem de qualquer coisa [...]" (VOLOŠINOV, 2010, p. 129, trad. nossa), mas "um corpo físico, por assim dizer, idêntico a ele mesmo, nada significa, coincidindo inteiramente com seu caráter de dado único e natural" (VOLOŠINOV, 2012, p. 128, trad. nossa). A referência ao pão e ao vinho no universo cristão também é por ele citada como exemplo de metamorfose de instrumento a signo: "por exemplo, o pão e o vinho tornam-se símbolos religiosos no sacramento cristão da comunhão. Mas um produto de consumo como tal não é em caso algum um signo" (VOLOŠINOV, 2012, p. 129, trad. nossa). Portanto, o homem virá a ser signo apenas na condição e na situação em que se remete para fora dele mesmo, como a foice e o martelo, como o pão e o vinho.

\section{Conclusão}

Ler livros com as crianças e para as crianças desvela um dos modos culturais dos atos de ler que são recriados e legados de uma geração a outra. Os signos, a literatura para crianças, os modos de 
ler do homem, seus gestos e atitudes formam um conjunto semiótico que medeia essas relações. Os seres humanos em diferentes gerações se relacionam, no caso aqui abordado, por uma forma de cultura - a literatura para crianças, que é uma das formas ideais na qual a criança deve mergulhar para dela se apropriar por meio de um outro, e, em seguida, recriá-la e legá-la às gerações subsequentes.

A convivência entre gerações durante dezenas de anos permite a apropriação e a transmissão da cultura. Suas relações históricas rompem fronteiras e compõem um grande cenário em que se banham as gerações, de modo mais superficial ou mais profundo, conforme a intensidade maior ou menor de suas relações. As gotas que formam esse cenário/oceano cultural são as recriações e as criações culturais constituídas por signos de toda natureza, uma verdadeira babel semiótica por meio da qual o homem se alimenta de cultura para poder se desenvolver em seu processo de humanização. Humanizar-se é, então, experimentar, viver o processo de apropriação dos signos culturais que medeiam as relações.

Professoras/bibliotecárias/pais que leem uma narrativa para crianças fazem parte dessas relações mediadas pelos signos. Eles próprios, com sua voz, seu corpo, seu olhar, suas entonações, com o seu modo de virar a página, de rolar a tela, se tornam formas ideais de cultura em processo de apropriação pelo outro. Ninguém gosta de formas ideais de cultura não conhecidas e não apropriadas, nem sabe, por isso, apreciá-las.

O papel dos homens se alarga, porque são eles, ao mesmo tempo, agentes das relações com a cultura escrita, mas são eles próprios e seus gestos os objetos culturais de apropriação e de transformação. Ensinar o ato de ler com suas múltiplas variações e compartilhar esses atos promovem o desenvolvimento do homem como espécie e estabelecem um real processo de humanização.

O adulto/professor não é, então, um mediador, uma estrada, como sugeriu Vigotski (apud NASCIMENTO, 2014), mas pode vir a ser um signo cultural, social e ideológico que encarna outros signos e suas manifestações. Forma, assim, um conjunto híbrido de signos que vai mediar as relações de uma geração a outra e compor o mundo complexo do processo de humanização. Sem o homem precedente, que já se apropriou da cultura, não haverá a apropriação correspondente pelo homem subsequente. Bibliotecários, professores e pais são esses homens históricos, sociais e culturais, responsáveis por legar tudo isso às crianças que já nasceram e às que ainda nascerão. Todas essas questões até então comentadas ficam por aqui, perambulando, mal acabadas, à procura de outras reflexões. 


\section{Mediators and literature for children}

\section{Abstract}

In the field of children's literature, the place occupied by adults is considered to be that of the mediator. The purpose of this article is to reaffirm that this place belongs to signs and, for that, it recovers the concept of ideological sign in Volochinov (18951936), the formation of the psyche and the mediating function of signs in Vigotski (1896-1934) and the precursor concept of mediators in Sorokin (1889-1968). The thesis to be defended considers men as human beings in a relationship mediated by signs organized in genders, which make up the field of children's literature. The conclusion points out that human attitudes, when dealing with literature, can become signs and that only in this aspect can man be part of a mediating sign set.

Keywords: Children's literature; Mediator; Ideological sign; Social fact.

\section{Nota}

1 As ortografias dos nomes citados obedecem ao disposto em cada obra referenciada. As traduções são de responsabilidade do autor.

\section{Referências}

NASCIMENTO, R. de O. Um estudo da mediação na teoria de Lev Vigotski e suas implicações para a educação. 2014. Tese (Doutorado em Educação) - Faculdade de Educação. Universidade Federal de Uberlândia. 2014.

TILKOWSKI, I. Volosinov em contexte. Essai d'épistemologie historique. Limoges: Édition Lambert Lucas, 2012.

VIGOTSKI, L. S. Quarta aula: a questão do meio na pedologia. Tradução de Márcia Pileggi Vinha. Psicologia USP, 2010, 21 (4), p. 681-701. Disponível em <https://www. scielo.br/scielo.php?script=sci_arttext\&pid $=$ S0103-65642010000400003 $>$. Acesso em: 27 jul. 2020.

VIGOTSKI, 1. Pensamiento y habla. Tradução de Alejando Ariel Gonzáles. Buenos Aires: Colihue, 2012.

VOLOŠINOV, V. N. Marxisme et Philosophie du Langage: les problems fondamentaux de la méthode sociologique dans la science du langage. Tradução de Patrick Sériot e Inna Tylkowski-Ageeva. Limoges: Lambert-Lucas, 2010.

VOLÓCHINOV, V. Marxismo e filosofia da linguagem: problemas fundamentais do método sociológico na ciência da linguagem. Tradução de Sheila Grillo e Ekaterina Vólkova Américo. São Paulo: Editora 34, 2017. 